\title{
A Rare Association of Hydrops of Gall Bladder with Hepatitis E Infection
}

\author{
Sinha $\mathbf{R}^{1}$, Negi $\mathbf{V}^{2}$, Sawhney $\mathrm{MPS}^{3}$, Debnath $\mathrm{J}^{4}$ \\ ${ }^{1}$ Dr. Rahul Sinha MBBS, MD, DNB. Graded Specialist in Paediatrics, ${ }^{2}$ Dr. Vandana Negi MBBS, MD, DM Neonatology. \\ ${ }^{3}$ Dr. MPS Sawhney Comdt 167 MH, ${ }^{4}$ Dr. J Debnath MBBS, MD Radiology. All from Army Medical Corps, 167 MH C/O \\ 56APO, India.
}

Address for correspondence: Dr. Rahul Sinha, E-mail: drrahul_2000@yahoo.com

\begin{abstract}
Gall bladder distension with acute viral acalculous cholecystitis is an extremely rare event especially with Hepatitis $\mathrm{E}$ infection in paediatric cases with a high incidence of perforation, gallbladder necrosis and mortality. We report a four year old male child presenting with fever, vomiting, pain abdomen, mild hepatosplenomegaly and tenderness in right hypochondrium. Laboratory investigations revealed hyperbilirubinemia and elevated liver enzymes, but there was no evidence of bacterial or parasitic infection. Serology for viral hepatitis suggested acute Hepatitis E infection. Ultrasonographically distended inflamed gallbladder without calculous was observed. Finally acute acalculous cholecystitis due to Hepatitis E virus was diagnosed and the child responded to the conservative management.
\end{abstract}

Key words: Acalculous cholecystitis, Hepatitis E, Pericholecystic fluid, Gallbladder thickening.

\section{Introduction}

Acute hepatitis $E$ virus (HEV) infection is frequently encountered in developing countries especially in children ${ }^{1}$. Extra-hepatic manifestations of hepatitis virus include arthalgias, cutaneous vasculitis, cryoglobulinemia, and hemophagocytic syndrome. These manifestations are rare; when they do occur, they resolve with the resolution of hepatitis ${ }^{2}$.

During HEV infection, the gallbladder changes have never been reported in available literature. The gall bladder may undergo changes that include decreased fasting volume, increased wall thickening and appearance of biliary sludge ${ }^{3}$. Gallbladder involvement has been described in 50 to $98 \%$ of adults with acute viral hepatitis (especially hepatitis A), mild gallbladder wall thickening (GBWT) being the most common sonographic finding ${ }^{4}$.

Here we report a four years old male child with acute hydrops of gall bladder due to hepatitis $E$ virus infection.

\section{Case report}

A four years old male child presented to us with the complaints of fever, fatigue, nausea, vomiting, abdominal pain and loss of appetite of seven days duration. In the last three days, mother noticed that he was having dark urine and yellowish discolouration of eyes. There was no significant past medical history. There was no history of medication in recent past.

Physical examination showed an ill looking child with body temperature of $39.0^{\circ} \mathrm{C}$, heart rate of $110 /$ minute, respiratory rate of $28 /$ minute and blood pressure of $100 / 60 \mathrm{mmHg}$. There was scleral icterus. There was a tender globular lump about $4 \times 2 \mathrm{~cm}$ which was firm in consistency and felt in the right hypochondrium that was likely to be a gall bladder lump. Laboratory studies revealed the following: haemoglobin $12.7 \mathrm{mg} / \mathrm{dL}$; white blood cell (WBC) 10200/mm $\mathrm{mm}^{3}$, platelets $1,65,000 / \mathrm{mm}^{3}$, alanine aminotransferase (ALT) $2915 \mathrm{U} / \mathrm{L}$ (7-40 U/L), aspartate aminotransferase (AST) $3830 \mathrm{U} / \mathrm{L}$ (7-40 U/L), total serum bilirubin $5.38 \mathrm{mg} / \mathrm{dL}(0.3 \mathrm{mg} / \mathrm{dL})$; with a direct fraction of $2.62 \mathrm{mg} / \mathrm{dL}$ alkaline phosphates $1574 \mathrm{U} / \mathrm{L}$ (38-155 U/L), gamma-glutamyltranspeptidase (GGT) $194 \mathrm{U} / \mathrm{L}$ (15-60 U/L), albumin $3.4 \mathrm{~g} / \mathrm{dl}$, prothrombin time 18.7 seconds, erythrocyte sedimentation rate 20 $\mathrm{mm} / \mathrm{h}$, C-reactive protein $0.74 \mathrm{mg} / \mathrm{dL}(0-5 \mathrm{mg} / \mathrm{dL})$, Blood culture was sterile, HBsAg (-ve), anti-HBclgM (-ve), antiHCV (-ve), anti-HAV IgM (-ve) and anti-HEV IgM (+ve). Abdominal ultrasound revealed hepatomegaly, hydropic 
gallbladder without calculus, thickened gallbladder wall and pericholecystic fluid (Fig 1).

The child was started on injectable antibiotics and IV fluids. Within seven days of admission to the hospital, his jaundice, abdominal pain, vomiting frequency, temperature, skin icterus and abdominal tenderness decreased. The right side of the abdomen was less tender. Repeated biochemical study showed total bilirubin $2.9 \mathrm{mg} / \mathrm{dL}$, with a direct fraction of 1,8 $\mathrm{mg} / \mathrm{dL}, \mathrm{ALT}: 1025 \mathrm{U} / \mathrm{L}$ and AST: $1233 \mathrm{U} / \mathrm{L}$ and alkaline phosphates: $974 \mathrm{U} / \mathrm{L}$ (38-155 U/L). Abdominal ultrasound revealed hepatomegaly, and reduced size of gall bladder compared to earlier report. Presently the child is afebrile and doing well. He was discharged on the 10th day of admission in good clinical condition and with considerable improvement in biochemical tests $\mathrm{He}$ is kept under follow up in our OPD.

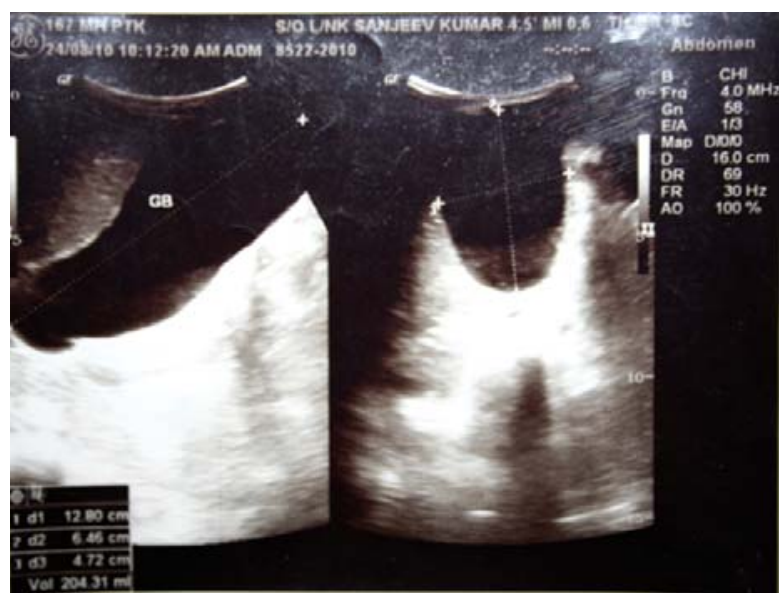

Fig 1: Abdominal sonography showing distended gall bladder with thickened wall

\section{Discussion}

Hepatitis $E$ virus is a self-limiting, usually asymptomatic infection that occurs predominantly among children. It is generally catastrophic in pregnant females. In some patients, gallbladder abnormalities such as increased thickness of the gallbladder wall and sludge formation were described. These children presenting with acute hepatitis had an initial clinical onset suggestive of acute cholecystitis (pain and guarding in the right hypochondrium, fever and delayed jaundice) associated with important ultrasonographic findings including: increased gallbladder wall thickness and rarely hydrops of gall bladder.
Early studies have shown that during viral hepatitis, the gallbladder may undergo changes that include decreased fasting volume, increased wall thickening and appearance of biliary sludge. These morphofunctional events are transient and gradually disappear when viremia becomes low. Gallbladder wall thickness returns to normal in these patients within few days. These patients do not require surgical intervention.

There is no case report of Hepatitis E with hydrops of gall bladder in children. Only few cases of gallbladder involvement during HAV infection were reported in medical literature ${ }^{5}$. The exact reason for the involvement of gall bladder with hepatitis $E$ infection requires further research. It should be kept in mind that although rare, acute viral cholecystitis can develop during the course of acute HEV infection in children ${ }^{6}$. We suggest that the right upper quadrant pain, high temperature, severe vomiting, severe jaundice during acute hepatitis $E$ is, at least in part, may be caused by gallbladder involvement. Paediatricians and paediatric surgeons must be familiar with the possibility of gallbladder and pancreatic involvement during HEV infection to avoid unnecessary invasive procedures.

\section{References}

1. Ozaras R, Mert A, Yılmaz $M H$, et al. Acute viral cholecystitis due to hepatitis A virus infection. J Clin Gastroenterol 2003;37:79-81.

2. Bell BP, Shapiro CN. Hepatitis A Virus. In: Principles and Practice of Pediatric Infectious Diseases, Long SS, Plckering LK, Prober CG (eds), 2nd ed, Churchill-Livingstone, New York, 2003;1118-1194.

3. Portincasa P, Moschetta A, Di Ciaula A, et al. Changes of gallbladder and gastric dynamics in patients with acute hepatitis A. Eur J Clin Invest 2001;31:617-22.

4. Sharma MP, Dasarathy S. Gallbladder abnormalities in acute viral hepatitis: a prospective ultrasound evaluation. J Clin Gastroenterol 1991;13:697-700.

5. Klar A, Branski D, Nadjari M, et al. Gallbladder and pancreatic involvement in hepatitis A. J Clin Gastroenterol 1998;27:143-145.

6. Nanda SK, Yalcinkaya K, Panigrahi AK, Acharya SK, Jameel, S, Panda SK, 1994. Etiological role of hepatitis $E$ virus in sporadic fulminant hepatitis. $J$ Med Virol 42:133-137.

\section{How to cite this article?}

Sinha R, Negi V, Sawhney MPS, Debnath J. A Rare Association of Hydrops of Gall Bladder with Hepatitis E Infection. J Nepal Paediatr Soc 2011;31(3):222-223. 